\title{
Regional variation in healthcare spending and mortality among senior high-cost healthcare users in Ontario, Canada: a retrospective matched cohort study
}

Sergei Muratov ${ }^{1,2^{*}}$ (D) Justin Lee ${ }^{1,3,4,5}$, Anne Holbrook ${ }^{1,4}$, Andrew Costa ${ }^{1,6,7}$, J. Michael Paterson ${ }^{6,11}$, Jason R. Guertin ${ }^{8,9}$, Lawrence Mbuagbaw ${ }^{1,10}$, Tara Gomes ${ }^{6,12,13}$, Wayne Khuu ${ }^{6}$ and Jean-Eric Tarride ${ }^{1,2,7}$

\begin{abstract}
Background: Senior high cost health care users (HCU) are a priority for many governments. Little research has addressed regional variation of HCU incidence and outcomes, especially among incident HCU. This study describes the regional variation in healthcare costs and mortality across Ontario's health planning districts [Local Health Integration Networks $(\mathrm{LHIN})]$ among senior incident $\mathrm{HCU}$ and non-HCU and explores the relationship between healthcare spending and mortality.

Methods: We conducted a retrospective population-based matched cohort study of incident senior HCU defined as Ontarians aged $\geq 66$ years in the top 5\% most costly healthcare users in fiscal year (FY) 2013. We matched HCU to nonHCU (1:3) based on age, sex and LHIN. Primary outcomes were LHIN-based variation in costs (total and 12 cost components) and mortality during FY2013 as measured by variance estimates derived from multi-level models. Outcomes were risk-adjusted for age, sex, ADGs, and low-income status. In a cost-mortality analysis by LHIN, risk-adjusted random effects for total costs and mortality were graphically presented together in a cost-mortality plane to identify low and high performers.

Results: We studied 175,847 incident HCU and 527,541 matched non-HCU. On average, 94 out of 1000 seniors per LHIN were HCU $(C V=4.6 \%)$. The mean total costs for HCU in FY2013 were 12 times higher that of non-HCU $(\$ 29,779$ vs. $\$ 2472$ respectively), whereas all-cause mortality was 13.6 times greater (103.9 vs. 7.5 per 1000 seniors).

Regional variation in costs and mortality was lower in senior HCU compared with non-HCU. We identified greater variability in accessing the healthcare system, but, once the patient entered the system, variation in costs was low. The traditional drivers of costs and mortality that we adjusted for played little role in driving the observed variation in HCUs' outcomes. We identified LHINs that had high mortality rates despite elevated healthcare expenditures and those that achieved lower mortality at lower costs. Some LHINs achieved low mortality at excessively high costs.

Conclusions: Risk-adjusted allocation of healthcare resources to seniors in Ontario is overall similar across health districts, more so for HCU than non-HCU. Identified important variation in the cost-mortality relationship across LHINs needs to be further explored.
\end{abstract}

Keywords: Senior high-cost users, Small area variation, Healthcare expenditures, Mortality

\footnotetext{
* Correspondence: muratos@mcmaster.ca

${ }^{1}$ Department of Health Research Methods, Evidence, and Impact, McMaster

University, Hamilton, ON, Canada

${ }^{2}$ Programs for Assessment of Technology in Health (PATH), The Research

Institute of St. Joe's Hamilton, St. Joseph's Healthcare, Hamilton, ON, Canada

Full list of author information is available at the end of the article
}

(c) The Author(s). 2018 Open Access This article is distributed under the terms of the Creative Commons Attribution 4.0 International License (http://creativecommons.org/licenses/by/4.0/) which permits unrestricted use, distribution, and reproduction in any medium, provided you give appropriate credit to the original author(s) and the source, provide a link to the Creative Commons license, and indicate if changes were made. The Creative Commons Public Domain Dedication waiver (http://creativecommons.org/publicdomain/zero/1.0/) applies to the data made available in this article, unless otherwise stated. 


\section{Background}

High-cost health care users (HCU), a minority of individuals who consume a large proportion of health care resources, are a diverse group [1]. Due to their high burden on the healthcare system, a better understanding of various segments of the HCU population is needed to develop evidence-informed health care policy $[1,2]$. In particular, seniors (patients 65 years of age and older), who account for about $15 \%$ of the population in the province of Ontario, account for approximately $60 \%$ of the total costs incurred by all $\mathrm{HCU}$ in the province [3-5]. Further, nearly half of senior HCU each year are incident cases $[6,7]$. These "new" cases represent a stratum of the HCU population that can potentially be a target of preventative interventions and management, but they have not been adequately studied, especially in the context of regional variation.

Large geographical disparities in health care services have been documented globally $[8,9]$. In Canada, marked regional variation has been identified in key healthcare services such as hospitalization [10], surgical procedures [11, $12]$, and use of prescription drugs $[13,14]$. In contrast to this evidence of disparities in individual healthcare services, there is little information on variation in healthcare spending in the Canadian provincial context. While reports on regional variation in healthcare spending, especially the Medicare costs, have dominated the US political debate for more than a decade [15-19], only one Canadian study (British Columbia[BC]) has investigated regional variation in healthcare expenditures and found it to be modest [20]. While very informative, the $\mathrm{BC}$ study was not intended to investigate seniors specifically, not to mention senior HCU. Moreover, except for the total healthcare spending, the $\mathrm{BC}$ study did not provide information on variation among individual cost components such as hospitalization and physician costs which limits our understanding of the processes of care that contribute to higher or lower variation [21].

Understanding regional variation in health services utilization, costs and health outcomes can inform health services planning for senior patients, including senior $\mathrm{HCU}$, in several ways. First, it allows planners to explore potential drivers of variation that deserve attention by describing the distribution of patient and care characteristics across health districts [22, 23]. Second, evidence suggests that planning and implementing health services with an "equity lens" can improve equity in resources allocation [24] and healthcare services use [25-27], and reduce regional variation in outcome distribution [28]. Third, measuring the relationship between costs and health outcomes among health regions is critical for policy makers to identify geographical "pockets" of efficient care (areas with lower spending and better outcomes). Recent studies have reported the level of inefficiency in Canada at $20 \%$ [29] with significant variations across Canadian provinces [30]. Moreover, even though available evidence of healthcare regional variation and efficiency has led policy makers to entertain the idea of cutting reimbursement rates in higher-spending regions $[15,31]$ or to establish new provider-physician integrated entities with spending benchmarks (accountable care organizations) [32], there is still a gap in our knowledge as to how regional disparities in healthcare spending affect regional patterns of health outcomes [33]. The lack of evidence on geographical variation in health outcomes seems to have contributed to the gap [34, 35].

To better inform decision and policy making in Ontario and fill a gap in the literature, the objectives of this study were: 1) to estimate regional variation in healthcare costs (total and by cost categories) and mortality among incident senior HCU compared to senior non-HCU; and 2) to examine the relationship between health spending and mortality by health districts for senior incident HCU compared to senior non-HCU.

\section{Methods \\ Study design}

A retrospective population-based matched cohort study was conducted using province-wide linked administrative data. More details on the study population and data sources are published elsewhere but are briefly summarized below [36].

\section{Study population}

We generated a cohort of all incident senior $\mathrm{HCU}$ in the province of Ontario. This cohort was defined as consisting of seniors (aged $\geq 66$ years) with annual total healthcare expenditures within the top 5\% threshold of all Ontarians in the 2013 Ontario government fiscal year (FY2013) (i.e. incident year), and not in the top 5\% in the 2012 fiscal year (FY2012).The threshold of 5\% to define HCU is aligned with previous Canadian studies of this population [3, 7, 37, 38].The incident HCU cohort was matched to a cohort of non-HCU using a 1:3 matching ratio, without replacement based on age at cohort entry (+/-1 month), sex and residence (based on Local Health Integration Networks [LHIN]). The "non-HCU" cohort was defined as those whose annual total health care expenditures in the 2012 and 2013 fiscal years were both below the financial threshold of the top $5 \%$ of all Ontarians in the respective year.

\section{Data sources}

The patient-level dataset was created using 19 health administrative databases [36]. These datasets were linked using unique encoded identifiers and analyzed at the Institute for Clinical Evaluative Sciences (ICES) [39]. Health care expenditures were calculated using a person-level health utilization costing algorithm [40]. Total healthcare expenditures were comprised of 12 separate health service cost categories. Hospital costs were the sum of costs 
associated with inpatient care and same-day surgery. Physician costs were the sum of fee-for-service billings and capitation payments. Costs reported in this study are based on patients' geographic location of residence. Costs are expressed in 2013 Canadian Dollars.

\section{Geographic unit of analysis}

We used LHINs, Ontario's regional health districts, as the geographic unit of analysis. Ontario's 14 LHINs are responsible for the funding, planning and management of hospital- and community-based health services delivered to all residents within their geographic boundaries [41]. Services covered by the LHINs include most of hospital and community care such as inpatient care, long-term and home care, community mental health, rehabilitation and hospices among others [42], but exclude physician services, which are funded from a separate envelope.

\section{Variables}

The study population was described at baseline (i.e., the year before $\mathrm{HCU}$ incident status), including comparisons of socio-demographic determinants (age, sex, residence, low income), health status (degree of morbidity, proportion of chronic conditions) and health system factors (e.g., number of physicians in the circle of care and whether a geriatrician was visited) between $\mathrm{HCU}$ and matched non-HCU. Subjects with low income status were identified based upon net household income reported to receive public drug benefit subsidy in FY2012. Compared to census-based neighborhood income measures, the Ontario Drug Benefit (ODB)-based low income status is a better reflection of personal income, as it relies upon actual net income. For a small proportion of HCU (3\%) and non-HCU (13\%) who did not fill a prescription in FY2012, low-income status was defined as census neighborhood income quintile 1 . Rurality was defined using the Rural Index of Ontario (RIO): an ordinal measure ranging from 0 (urban) to 100 (rural) that considers population density and travel time to the nearest health facility [43].

Several measures were employed to describe health status. Level of morbidity was measured using Johns Hopkins Aggregated Diagnosis Groups (ADGs) that are derived from Johns Hopkins Adjusted Clinical Groups (ACGs): a person-focused, diagnosis-based way to measure patients' illness [44]. In addition, the proportions of patients with prior malignancy and mental health conditions were computed using John Hopkins Expanded Diagnosis Clusters (EDCs). Finally, the proportions of patients with chronic obstructive pulmonary disease, congestive heart failure, diabetes, and rheumatoid arthritis were estimated using ICES-derived, validated chronic disease cohorts $[45,46]$.

\section{Outcomes}

Several outcomes were assessed. HCU rate for each LHIN was defined as the number of senior HCU over the total number of seniors residing in the LHIN per 1000 population. Mean per capita total healthcare expenditures and mean per capita health expenditures for each care category were calculated as the costs incurred in the incident year over the total population in the HCU and non-HCU cohort. Finally, mortality for each cohort was defined as the prevalence of all-cause death within the incident year.

\section{Statistical analysis}

Descriptive statistics (counts [\%]; mean [SD] or median [Q1, Q3]) were summarized for baseline individual characteristics and outcomes. Characteristics of subjects in both HCU and non-HCU cohorts were compared using absolute standardized differences (SDD). SDDs of more than 0.1 are considered to indicate meaningful differences between the cohorts [47]. To describe the variation between the LHINs in terms of costs and outcomes, the coefficient of variations (CVs) defined as the ratio of the standard deviation to the mean were determined.

Because the calculated intra-class correlation coefficient (ICC) pointed toward statistically significant clustering within the LHINs across most of the cost components and mortality in both cohorts (Additional file 1), we fitted a mixed effects model to estimate between-region variation and risk-adjust for age, sex, the number of ADGs per patient, and low-income status for both costs and mortality. Compared to the CV or other summary statistics characterizing regional variation, these models provide additional information, including the between-LHIN variance estimate and the proportion of the observed variation explained by patient characteristics.

We specified the following general equation (Additional file 2):

$$
\mathrm{y}_{\mathrm{ij}}=\left(\operatorname{Beta}_{0}+\mathrm{u}_{0 \mathrm{j}}\right)+\sum \operatorname{Bet}_{\mathrm{ij}} \mathrm{X}_{\mathrm{ij}}+\mathrm{e}_{\mathrm{ij}}
$$

where $y i j$ - the outcome (costs or mortality) in patient i from $\mathrm{LHIN}_{\mathrm{j}}$; $\mathrm{Beta}_{0}$ - the provincial mean; $u 0 j$ - the random effect for each LHIN that is assumed $u 0 j \sim N(0, \sigma 2 u)$; Beta $_{i j}$ - the fixed effects of individual level characteristics; $X i j$ - the vector of covariates at the individual level; $e i j$ - the residual error.

This type of models assumes that the mean outcome value for each LHIN vary randomly according to a normal distribution $(u 0 j \sim N(0, \sigma 2 u))$ whereas the effect of the patients' covariates is fixed among the LHINs. The main interest in this type of analyses is the random effect $(u 0 j)$ which characterizes variation between LHINs, where $\sigma 2 u$ is the direct estimate of the variance. 
For the mortality analyses, logistic regression was conducted by fitting generalized linear mixed models (GLMM) according to the general model specification provided above. To model healthcare expenditures, two methods were used based on the proportion of zero costs values in the data. Zero cost values arise when healthcare resources are not consumed (e.g. no contact with healthcare system or no hospitalization). For healthcare categories with no zero costs values GLMM were used. In the presence of zero costs values in the data, Hurdle mixed models were used to account for zeros $[48,49]$. Hurdle models, also referred to as a two-part model, assumes that costs are generated by two statistically different processes. A binomial distribution (part 1) was used to determine whether any costs were incurred, and a gamma distribution (part 2) was employed to model positive costs (instances when costs $>0$ ) [49-51]. Expected costs resulting from Hurdle models are then calculated by multiplying the probability of observing a cost by the value of the costs when observed. LHIN-specific random effects were incorporated into each part of the model to estimate between-LHIN variation in the probability of incurring any costs $(\sigma 2 u 1)$ and variation in costs once they were incurred $(\sigma 2 u 2)$, resulting into two random effects values. Similarly, the fixed effects associated with the individual level characteristics were included in each part of the Hurdle model.

Unadjusted and risk adjusted models were compared using both the likelihood ratio test (LRT) that follows a chi-squared distribution ( $p$-value has to be less than 0.05) and information criteria (e.g., Akaike and Bayesian: lower values equal better fit) [52-54]. Statistical significance of coefficients was considered at alpha $=0.05$. We also compared the observed data with predicted values by LHIN to investigate model adequacy. The coefficient of determination $\mathrm{R}^{2}$ was calculated to measure the proportion of the observed regional variation in outcomes explained by the covariate for each model (please see Additional file 2) [55, 56]. To assess uncertainty around the estimates of the random effects, we generated a bootstrap 95\% confidence interval (CI) from the bootstrap sample of 1000 by looking at the 2.5th and 97.5th percentiles in this distribution.

To determine whether certain regions are more efficient than others, we examined the relationship between total healthcare spending (positive costs) and mortality in both cohorts. Building on an approach previously employed for hospital profiling $[57,58]$, the risk-adjusted random effects for total costs and mortality were first ordered from the smallest to the largest and then graphically presented together in a cost-mortality plane, one for each cohort. LHINs located at the left bottom quadrant of the plots (where the $\mathrm{X}$ axis represents mortality and the $\mathrm{Y}$ axis costs) are more efficient than others provided that the $\mathrm{CI}$ of random effects for both total costs and mortality does not cross 0. Analyses were conducted using SAS software version 9.4 (SAS Institute Inc., Cary, NC, USA). The NLMIXED procedure was used to fit all the models. To visualize HCU rates between LHINs, a heat map was created using QGIS (Quantum geographic information system, https://qgis.org).

\section{Results}

\section{Baseline characteristics}

We included 703,388 subjects (HCU $=175,847$, non-$\mathrm{HCU}=527,541)$. The HCU were similar to non-HCU with respect to age, sex, the proportion residing in urban centres, and the number of low-income subjects (Table 1). However, compared to non-HCU, HCU tended to have a higher number of comorbidities, and a larger proportion of subjects with a malignancy, common chronic diseases, and mental health issues. HCU were dispensed a higher number of prescription drugs, had more physicians involved in their circle of care, and were seen by a geriatrician more often. Additional file 3 provides more information on the variation in these characteristics between the 14 LHINs.

\section{$\mathrm{HCU}$ rate}

Figure 1 shows the distribution of $\mathrm{HCU}$ among the 14 health regions. The size of LHINs' senior HCU population ranged from a low of 88.1 per 1000 seniors (Central 08

Table 1 Patient baseline individual and care characteristics, preincident year

\begin{tabular}{llll}
\hline Characteristic & HCU & Non-HCU & SDD \\
& Mean (SD) & Mean (SD) & \\
\hline Age: subgroup (\%) & & & \\
$66-74$ & $39.7(2.5)$ & $39.7(2.5)$ & 0.00 \\
$75-84$ & $39.9(0.8)$ & $39.9(0.8)$ & 0.00 \\
$\geq 85$ & $20.5(2.5)$ & $20.5(2.5)$ & 0.00 \\
Sex (F, \%) & $52.7(1.3)$ & $52.7(1.3)$ & 0.00 \\
Rurality (urban, \%) & $61.8(27.6)$ & $62.7(28.0)$ & 0.03 \\
Low income senior (\%) & $17.6(5.2)$ & $16.8(5.7)$ & 0.01 \\
Number of ADGs (mean) & $10.1(0.4)$ & $7.9(0.3)$ & 0.50 \\
Malignant neoplasms (\%) & $32.2(2.6)$ & $23.4(3.2)$ & 0.20 \\
Common chronic conditions* (\%) & $60.6(2.4)$ & $44.8(2.3)$ & 0.30 \\
Mental health\# (\%) & $37.6(4.1)$ & $26.9(2.5)$ & 0.20 \\
Number of MDs involved in care & $8.1(0.5)$ & $5.6(0.3)$ & 0.50 \\
(mean) & & & \\
Seen by a geriatrician (\%) & $2.8(1.3)$ & $1.1(0.5)$ & 0.12 \\
Number of prescription drugs (mean) & $8.4(0.4)$ & $5.6(0.3)$ & 0.60 \\
Acute inpatient care (\%) & $3.8(1.1)$ & $2.1(0.7)$ & 0.10 \\
\hline
\end{tabular}

ADGs- Aggregated Diagnosis Groups; HCU- high-cost user; *ICES- derived common chronic conditions (either one of the following: CHF-congestive heart failure; COPD- chronic obstructive pulmonary disease; DM- diabetes, MImyocardial infarction, RA- rheumatoid arthritis); LHIN - Local Health Integrated Network; SD- Standard Deviation; \# includes any of mental health conditions among Expanded Diagnosis Clusters (PSY01-12); SDD - absolute standardized difference; SDD $\geq 0.1$ indicates a meaningful difference 


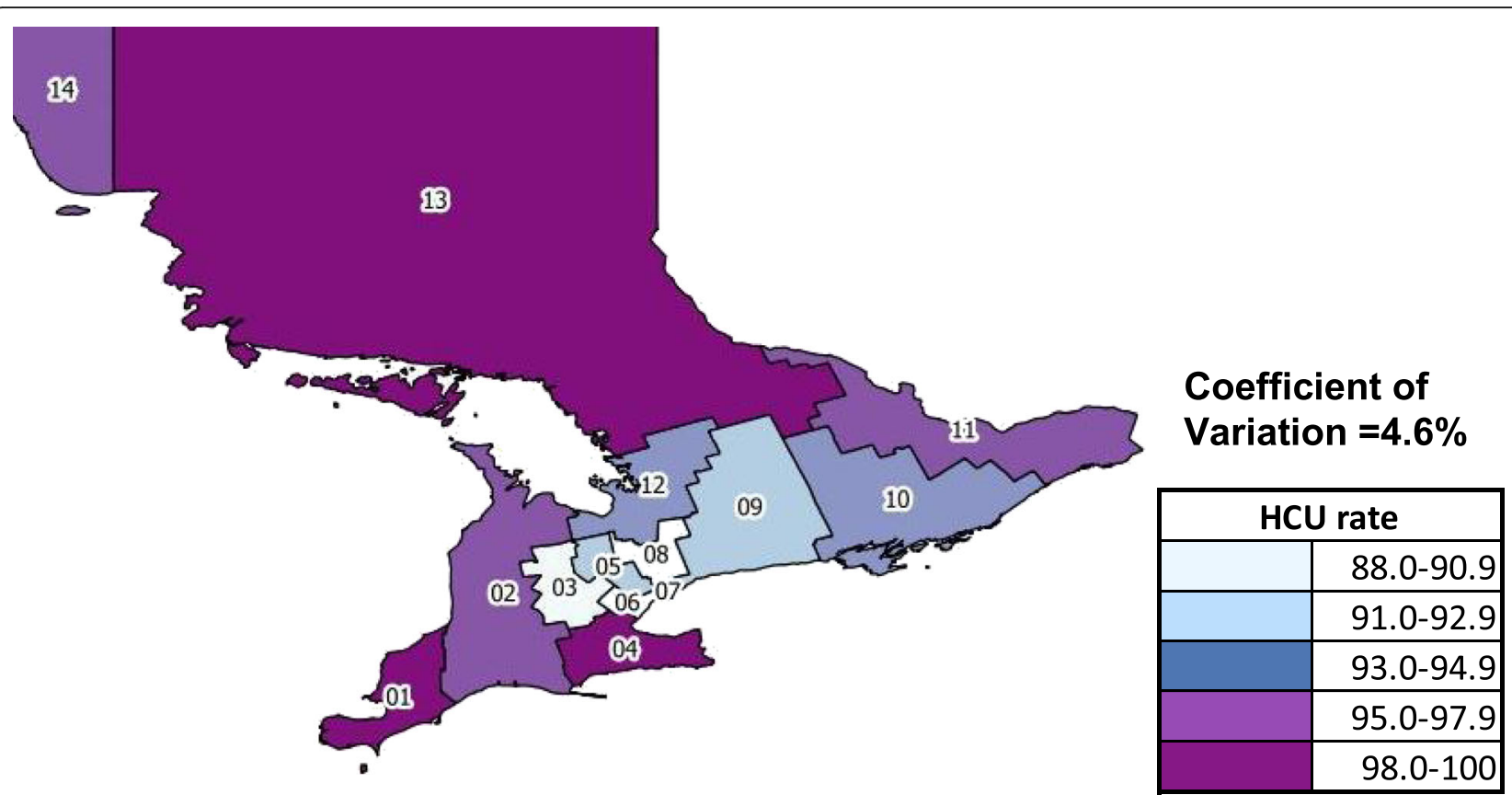

Fig. 1 HCU rate, per 1000 seniors. 01- Erie St. Clair; 02- South West; 03- Waterloo Wellington; 04- Hamilton Niagara Haldimand Brant; 05- Central West; 06- Mississauga Halton; 07- Toronto Central; 08- Central; 09- Central East; 10- South East; 11- Champlain; 12- North Simcoe Muskoka; $13-$ North East; 14- North West

LHIN) to a high of 100.2 per 1000 seniors (North East 13 LHIN).One of the northernmost regions of Ontario (North East 13 LHIN), and two health regions in the southwest of the province (Erie St. Clair 01 LHIN and Hamilton 04 LHIN) had the highest rates of HCU in the province, whereas health regions in close proximity to Toronto tended to exhibit the lowest rates. Overall variation in HCU rates across the province had a CV of $4.6 \%$.

\section{Unadjusted and adjusted costs and mortality by LHIN}

The mean total 1-year observed costs per individual were $\$ 29,646 \mathrm{CAD}$ and $\$ 2452 \mathrm{CAD}$ for HCU and non-HCU, respectively. Hospital admissions represented the largest cost component among incident $\mathrm{HCU}$ accounting for $48.2 \%$ of the total costs. In non-HCU, prescription drugs were closely followed by physician costs as the top contributors to the total expenditures at 38.9\% and 35.8\%, respectively, while hospitalization accounted for $10.2 \%$. All-cause mortality during the incident year among $\mathrm{HCU}$ was 13.6 times greater that of non-HCU (104.2 vs. 7.7 per 1000 seniors, respectively). Additional file 4 presents the observed and adjusted mortality and costs (total healthcare expenditures and its components) as well as the associated CVs. As shown in the tables, there was a very good agreement between observed and adjusted mean values across the mortality and cost components in both cohorts suggesting a good fit of the data. CVs for total costs and mortality were $3 \%$ and $6.8 \%$ for the HCU cohort, indicating little variation between LHINs. Higher CV values were observed for several cost components such as complex continuing care (CV of 45.1\%), rehabilitation ( $\mathrm{CV}$ of $7.2 \%$ ), and dialysis (CV of $36.2 \%$ ), and CVs were higher for the non-HCU matched cohort. In all analyses that converged, the models incorporating patient individual covariates were preferred to the models without covariates as shown by the LRT tests and lower AIC and BIC values. For non-HCU, the two-part mixed effects models did not converge in 4 cost components (mental health, long-term care, complex continuing care, rehabilitation services) due to very low number of patients that incur these costs.

\section{Between-LHIN variation in mortality and costs}

Starting with mortality, the results of the mixed models indicate that the LHIN-specific variation in mortality (represented by the variance $\sigma 2 u$ ) was statistically significant and was 10 times as low compared to non-HCU (Table 2). All covariates were statically significant with the expected signs although the impact of the number of ADG was different for $\mathrm{HCU}$ and non-HCU. As shown by the values of the coefficient of determination $\mathrm{R}^{2}$, approximately $9 \%$ the observed variation in mortality among HCU is explained by patients' characteristics while this percentage is $18 \%$ for non-HCU.

Table 3 presents regression results for total costs among $\mathrm{HCU}$ and non-HCU. Since all the HCU had a contact with the healthcare system and incurred a cost, we used a GLMM to fit the data for the HCU. Results indicated that the LHIN-specific variation was small but 
Table 2 Regression results: mortality (adjusted, log scale)

\begin{tabular}{lll}
\hline Mortality & & \\
\hline Variables & HCU\# & Non-HCU\# \\
& Coefficient (SE) & Coefficient (SE) \\
Variance in mortality, o2u & $0.005(0.003)^{*}$ & $0.051(0.021)^{*}$ \\
Intercept & $-7.154(0.087)^{*}$ & $-13.883(0.201)^{*}$ \\
Age & $0.071(0.002)^{*}$ & $0.109(0.003)^{*}$ \\
Sex, M & $0.346(0.017)^{*}$ & $0.392(0.033)^{*}$ \\
ADG & $-0.04(0.002)^{*}$ & $0.052(0.004)^{*}$ \\
Low income status & $0.091(0.02)^{*}$ & $0.227(0.039)^{*}$ \\
R $^{2}, \%$ & $8.8 \%$ & $17.9 \%$ \\
LRT (Chi2 dist, $p<0.05)$ & 5207.2 & 2800.21
\end{tabular}

\# - Estimated through a mixed effects two-part model; * - estimates were statistically significant at $p<.05$; ADGs- Aggregated Diagnosis Groups; HCUhigh-cost user; LHIN - Local Health Integrated Network; LRT- likelihood ratio test; $\mathrm{R}^{2}$ - coefficients of determination; SE- Standard Error

statistically significant $(\sigma 2 u 2)$. All covariates were statistically significant too but only $1.6 \%$ (i.e. $\mathrm{R}^{2}$ ) of the observed regional variation in total costs of senior $\mathrm{HCU}$ was due to patient characteristics. Because $9.4 \%$ of non-HCU incurred no costs at all, we fitted a mixed effects two-part model to the non-HCU total cost data. Since two distributions generate the data, the model generates two random-effects to estimate between-LHIN variation in the probability of incurring any costs $(\sigma 2 u 1)$ and variation in costs once they were incurred $(\sigma 2 u 2)$. As shown in this table, the variation $(\sigma 2 u 1)$ among HCU in system contacts overall was 65 times as high as $\sigma 2 u 2$, both estimates statistically significant. All covariates were statistically significant in explaining each part of the model. The values of $R^{2}$ for the non-HCU cohort indicated that $87 \%$ of the LHIN variation related to the probability of incurring a cost was explained by the covariates while only $19.7 \%$ of the variation once a cost was incurred was explained by patient characteristics of non-HCU.

In addition to the total costs, Additional file 5A-B presents variance estimates across the cost components in both cohorts ( $\sigma 2 u 1$, where available, and $\sigma 2 u 2$, log-scale). With the exception of the analysis of costs associated with physician visits, all cost components were analysed with two-part models. Overall, variation in incurred expenditures across cost components was higher compared with that of the total costs. Similarly, variation in the probability of positive costs was substantially greater. LHIN-specific variation in dialysis costs (both part 1 and part 2 of the model) had the highest significant values in HCU, whereas regional variation in cancer expenditures was an outlier among non-HCU. The covariates traditionally representing health care needs explained much of the observed variation in the probability of accessing healthcare: $\mathrm{R}^{2}$ for part 1 of the models ranged from 0.5 to $34.5 \%$ (HCU) and $6.8 \%$ to
Table 3 Regression results: total public healthcare expenditures (adjusted, log scale)

\begin{tabular}{|c|c|c|}
\hline Total costs & & \\
\hline \multirow[t]{2}{*}{ Variables } & HCU\# & Non-HCU\& \\
\hline & Coefficient (SE) & $\begin{array}{l}\text { Coefficient } \\
\text { (SE) }\end{array}$ \\
\hline $\begin{array}{l}\text { Variance in probability of incurring } \\
\text { costs, } \\
\sigma 2 u 1\end{array}$ & & $0.065(0.026)^{*}$ \\
\hline $\begin{array}{l}\text { Variance in costs once incurred, } \\
02 \mathrm{U} 2\end{array}$ & $\begin{array}{l}0.0009 \\
(0.0004)^{*}\end{array}$ & $0.001(0.001)^{*}$ \\
\hline Covariance between $\sigma 2 u 1$ and $\sigma 2 u 2$ & & $0.006(0.003)$ \\
\hline \multicolumn{3}{|l|}{ Probability (costs $\neq 0$ ) } \\
\hline Intercept & & $4.49(0.16)^{*}$ \\
\hline Age & & $\begin{array}{l}-0.067 \\
(0.002)^{*}\end{array}$ \\
\hline Sex, M & & $-0.205(0.03)^{*}$ \\
\hline ADG & & $1.018(0.009)^{*}$ \\
\hline Low income status & & $\begin{array}{l}-0.129 \\
(0.035)^{*}\end{array}$ \\
\hline \multicolumn{3}{|l|}{ Costs $>0$} \\
\hline Intercept & $9.74(0.02)^{*}$ & $5.946(0.025)^{*}$ \\
\hline Age & $0.008(0.0002)^{*}$ & $0.016(0.001)^{*}$ \\
\hline Sex, M & $0.064(0.003)^{*}$ & $0.044(0.005)^{*}$ \\
\hline ADG & $\begin{array}{l}-0.011 \\
(0.0004)^{*}\end{array}$ & $0.081(0.001)^{*}$ \\
\hline Low income status & $0.018(0.004)^{*}$ & $0.134(0.006)^{*}$ \\
\hline log_theta & $0.788(0.003)^{*}$ & $0.473(0.004)^{*}$ \\
\hline$R^{2}($ part 1$), \%$ & & $87.0 \%$ \\
\hline$R^{2}($ part 2$), \%$ & $1.6 \%$ & $19.7 \%$ \\
\hline LRT (Chi2 dist, $p<0.05)$ & 2333.0 & $88,500.57$ \\
\hline
\end{tabular}

\& - Estimated through GLMM; \# - Estimated through a mixed effects two-part model; * - estimates were statistically significant at $p<.05$; ADGs- Aggregated Diagnosis Groups; HCU- high-cost user; LHIN - Local Health Integrated Network; Log-theta- the logarithm of the shape parameter of gamma distribution; LRT- likelihood ratio test; $\mathrm{R}^{2}$ - coefficients of determination; SEStandard Error

$87.0 \%$ (non-HCU). In contrast, once the costs were incurred, the role of these covariates greatly diminishes. $\mathrm{R}^{2}$ for part 2 ranged from 0.3 to $5.1 \%$ (HCU) and $2.7 \%$ to $19.7 \%$ (non-HCU).

\section{Cost-mortality relationship}

To identify LHINs that are more efficient than others (e.g. lower spending and mortality), LHINs were ranked by random effects for total costs and mortality (Figs. 2 and 3). As shown in Figs. 2a-c presenting the random effects for each LHIN and the associated 95\% CIs among HCU, there were several LHINs in which the random effects were statistically significant for mortality (Fig. 2a) and costs (Fig. 2b). When costs and mortality were combined in a cost-mortality plane (Fig. 2c), only LHINs 1 , 3,4 and 7 had the random effects significant for both 


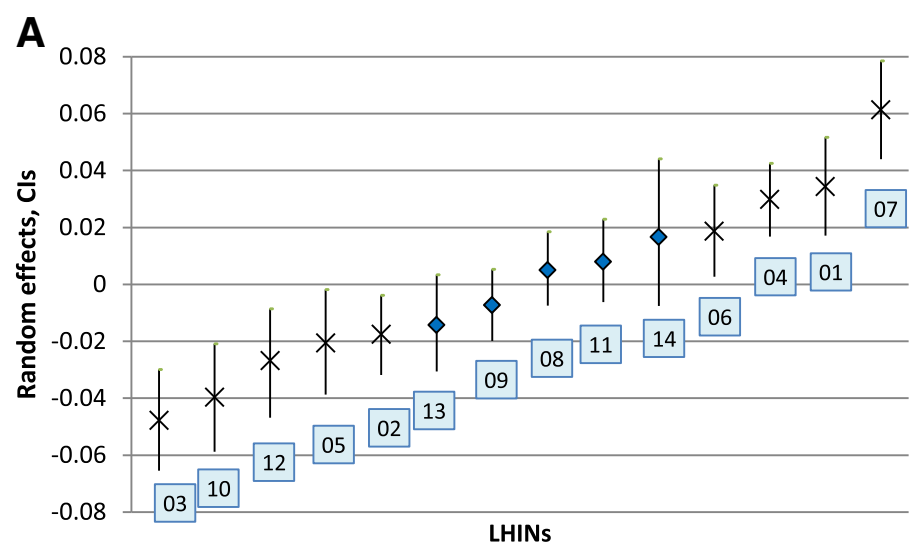

B

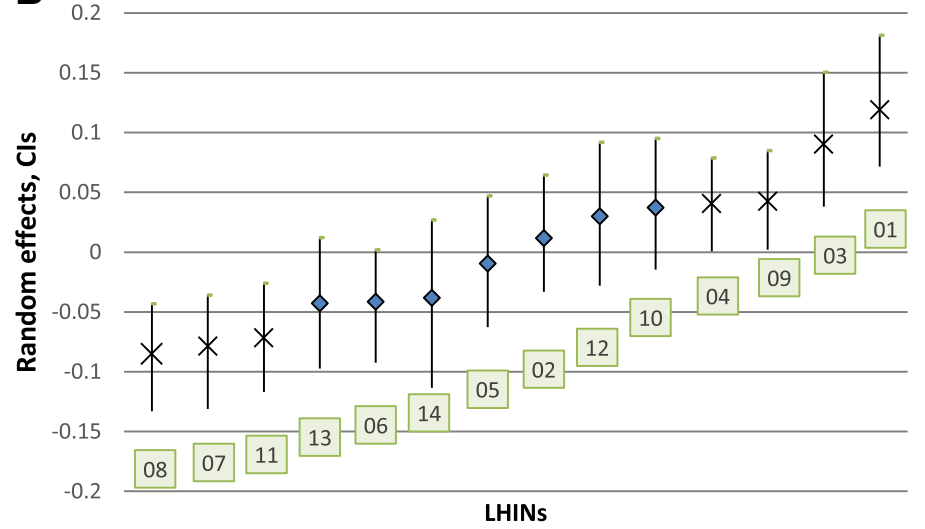

C

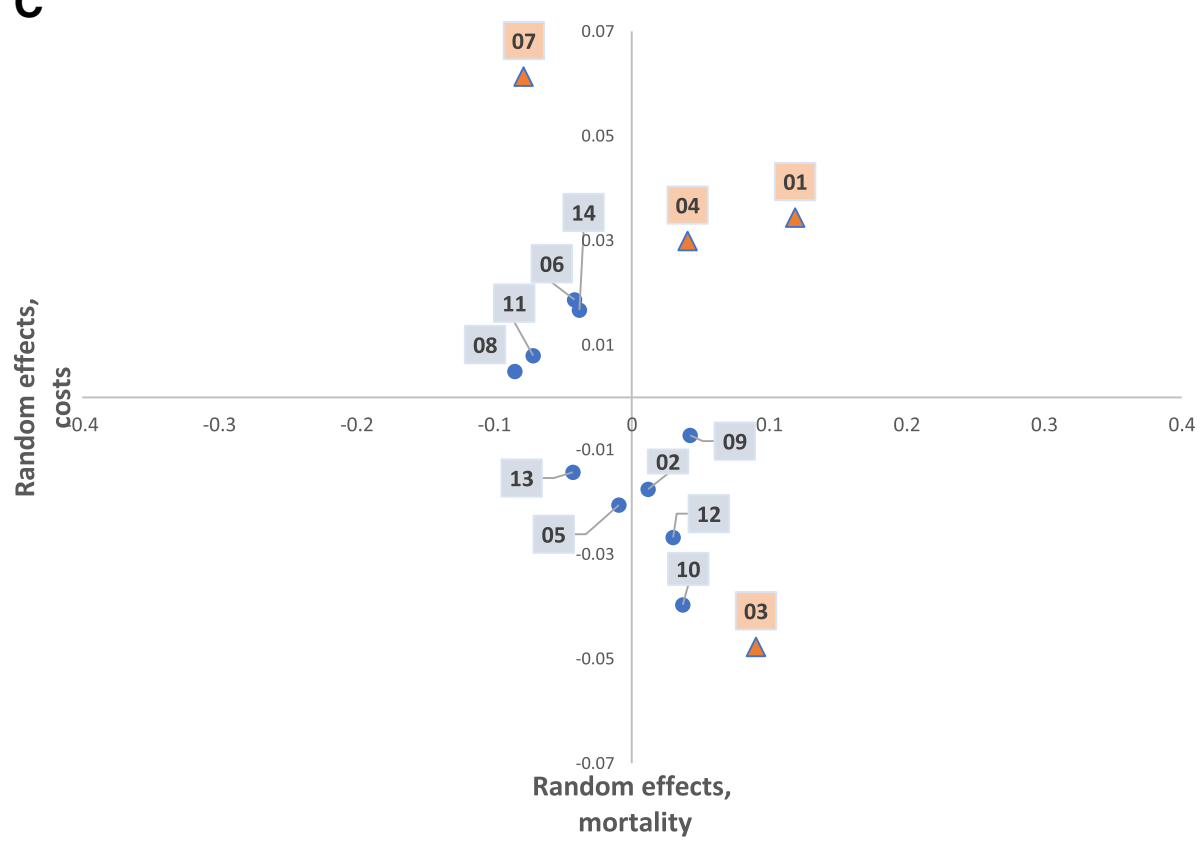

Fig. 2 (See legend on next page.) 
(See figure on previous page.)

Fig. 2 a: Ranking LHIN-specific random effects in total costs, HCU. Marked as X are statistically significant. b: Ranking LHIN-specific random effects in mortality, HCU. Marked as X are statistically significant. c: Cost-mortality relationship, HCU. Both total costs and mortality are adjusted for the regional factor, age, sex, ADGs, and low-income status; colored triangle indicates health district in which variation in both costs and mortality is statistically significant; 01- Erie St. Clair; 02- South West; 03- Waterloo Wellington; 04- Hamilton Niagara Haldimand Brant; 05- Central West; 06Mississauga Halton; 07- Toronto Central; 08- Central; 09- Central East; 10- South East; 11-Champlain; 12- North Simcoe Muskoka; 13- North East; 14- North West

total costs and mortality (marked as a triangle). Among those LHINs, none were in the lower bottom quadrant ("higher efficiency" pocket). Erie St. Claire 01 and Hamilton 04 LHINs (right upper) spend more and have a higher risk-adjusted mortality. Toronto Central 07 LHIN (left upper) has one of the lowest mortality rates, but it comes at a higher cost compared to other LHINs. In contrast, LHIN 3 had the lowest costs, but one of the highest mortality rates. For non-HCU (Fig. 3a-c), the list of LHINs with significant random effects for both total costs and mortality is broader and different from HCU. Several LHINs in close proximity to the Toronto area exhibit higher efficiency. On the opposite side, South West 02, South East 10, and North East 13 show signs of lower efficiency.

\section{Discussion}

This is the first Canadian study to examine geographic variation in healthcare costs and mortality among senior HCU. We found approximately a $14 \%$ difference between the highest (100.2 per 1000 seniors) and lowest (88.1 per 1000 seniors) incident senior HCU rates across the LHINs in Ontario. Overall regional variation in total costs and mortality was low in both cohorts, and lower among HCU compared to non-HCU. Our results indicate that traditional drivers of costs and mortality such as age, sex, comorbidity and income play little role in explaining variation in mortality and costs among HCU. Our analyses of individual cost components revealed greater variability in accessing the healthcare system, but, once the patient enters the system, variation in costs was low. Finally, LHINs vary in their costs per mortality rate, which deserves further analysis to determine whether policies or practices followed in high performing LHINs might be usable in other LHINs.

This study's results are important for several reasons. First, when regional variation is of interest, it is important to account for the regional factor in the model. In the literature on geographic healthcare variation, the authors seem to employ fixed effects models more often to describe variation in observed and predicted values through descriptive statistics (coefficient of variation, extremal quotient or its variations, etc.) $[15,20]$. The use of mixed effects models is less frequent but provides richer information when applied. As such, in addition to controlling for the regional effect, mixed effects models directly measure regional variability by estimating a variance component. In a two-part mixed effects models such as ours, it is also possible to estimate two components of between-LHIN variation: variation in the probability of costs incurred and variation in costs once incurred. Finally, we ran a fixed effects model in parallel (results available upon a request from authors). Comparing the findings with the mixed effects models showed closely matched coefficient estimates but more narrow standard errors which is an expected difference between the fixed effects and models with random effects.

Second, exploration of regional variation across multiple cost categories among seniors has not been reported for Canadian HCU or the general population. Even internationally, this is rarely done likely due to limited availability of such data. This study results indicate that reporting variation in total spending alone hides the contribution of individual cost components. The magnitude of some cost components such as hospitalization (a mean of \$13,677 among HCU) absorbs the variation of smaller components (a mean of $\$ 181$ in lab costs, respectively). It is particularly so among non-HCU where healthcare expenditures are substantially lower compared to HCU. As shown here, examining regional variation as a function of total costs only would present an incomplete picture: e.g., although small regional variation in total costs, there is a much greater variation in dialysis costs among $\mathrm{HCU}$. Also, comparison with non-HCU points to the fact that there is a very small number of non-HCU patients in several cost categories (e.g., mental health, rehabilitation, etc.) suggesting that incurring costs in these categories may convert a patient into an HCU.

Further, our results indicate that after adjustment, allocation of resources to seniors was similar across Ontario LHINs, more so for HCU compared to non-HCU, which is reassuring for healthcare planners. However, whether the allocation is truly equitable is unclear. Judging by the sign and CIs of coefficients in part 2 of the models, for example, the low-income status was associated with greater intensity of healthcare services across most of the cost components in both cohorts. Also, access to services may be an issue: patients with higher income status are more 
A

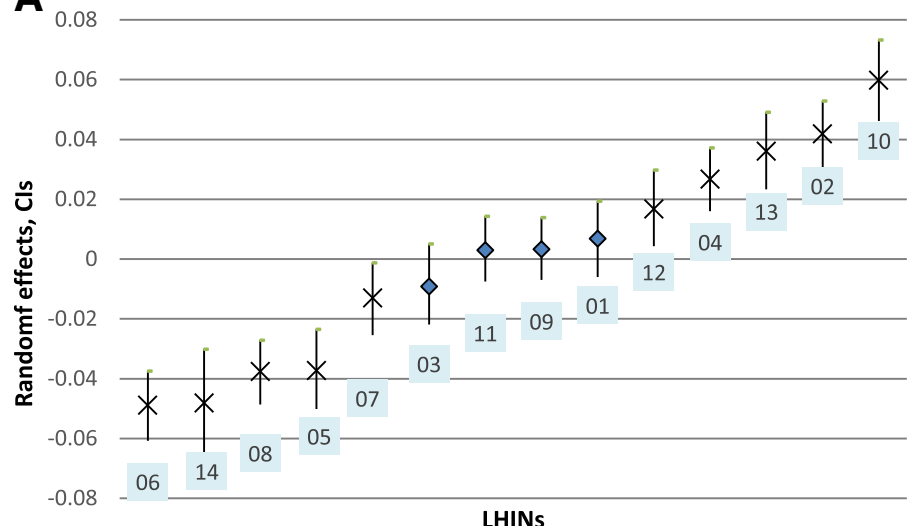

LHINs

B 0.5

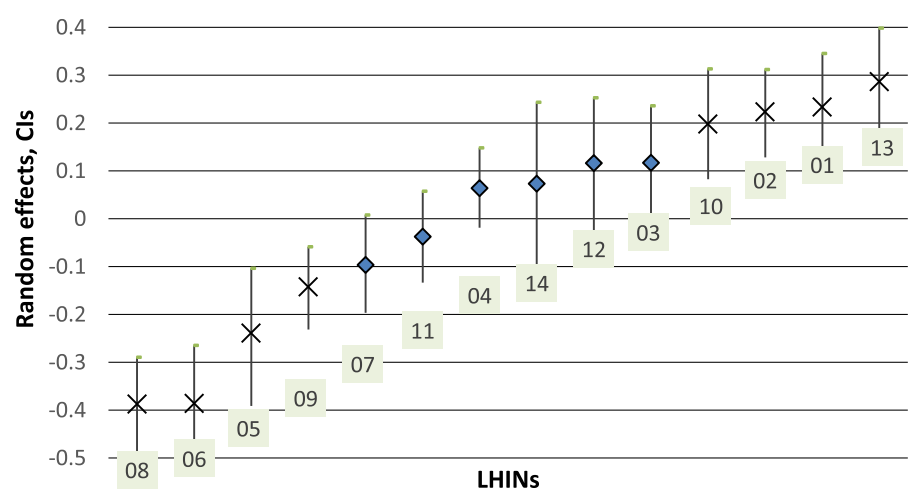

C

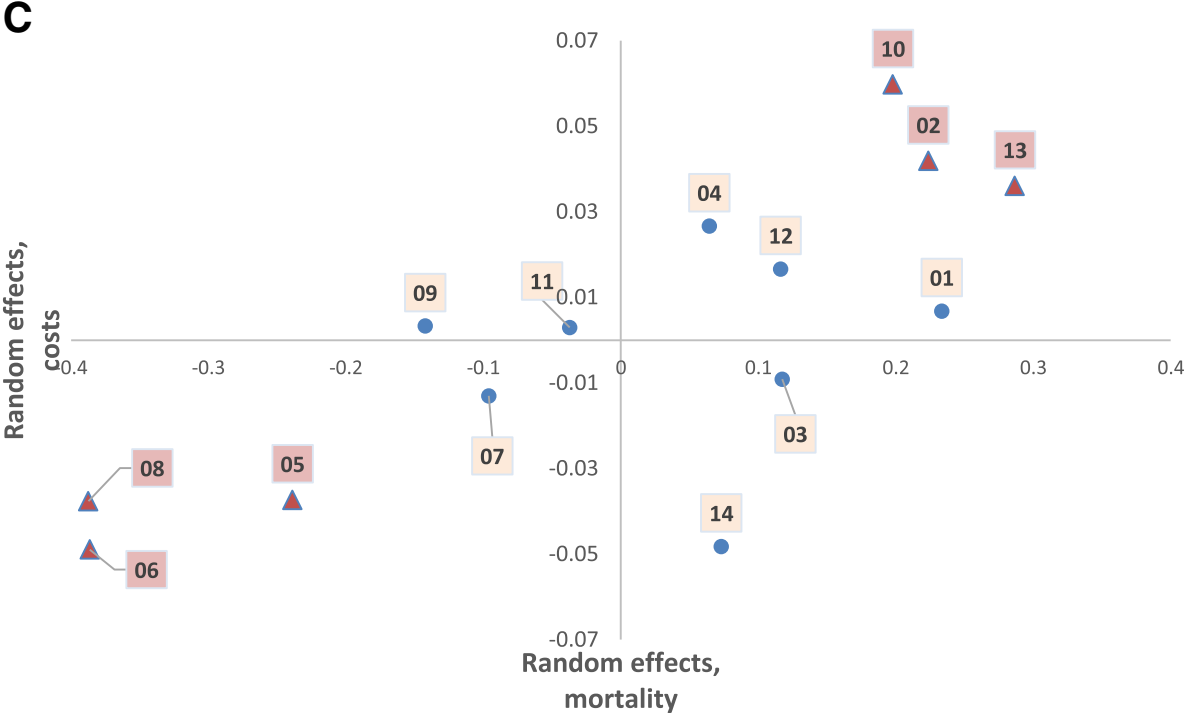

Fig. 3 a: Ranking LHIN-specific random effects in total costs, non-HCU. Marked as X are statistically significant. b: Ranking LHIN-specific random effects in mortality, non-HCU. Marked as X are statistically significant. c: Cost-mortality relationship, Non-HCU. Both total costs and mortality are adjusted for the regional factor, age, sex, ADGs, and low-income status; colored triangle indicates health district in which variation in both costs and mortality is statistically significant; 01- Erie St. Clair; 02- South West; 03- Waterloo Wellington; 04- Hamilton Niagara Haldimand Brant; 05-

Central West; 06- Mississauga Halton; 07- Toronto Central; 08- Central; 09- Central East; 10- South East; 11- Champlain; 12- North Simcoe Muskoka; 13- North East; 14- North West 
likely to enter the healthcare system. This is aggravated by much higher LHIN-specific variation in the probability of incurring costs. In particular, higher variation in dialysis and cancer costs may be a concern that requires further elucidation.

Finally, we have studied for the first time the relationship between costs and mortality for $\mathrm{HCU}$ and non-HCU across Ontario LHINs to explore health system performance from the efficiency angle. Efforts to examine the relationship between healthcare spending and outcomes, most often mortality, have been made globally applying various approaches $[16,30,59-65]$. The approach taken in our study builds on previous research that conducted hospital profiling $[57,58,66]$. As such, our results provide insight into the distribution of mortality in relation to resources spent across the Ontario LHINs by identifying districts of various cost-mortality performance. Although caution should be applied when interpreting the results of the study, e.g., variation in total costs across LHINs appears quite small, the observed differences in efficiency between health regions merit further examination to determine if health improvement could be achieved without additional healthcare spending.

\section{Strengths and limitations}

This study has several strengths. First, the dataset contained information on all incident senior $\mathrm{HCU}$ in the province at the time of data collection whereas the matched non-HCU represented approximately $25 \%$ of the total senior population in the province. Second, the study examines incident $\mathrm{HCU}$ cases which represents a shift in the focus of HCU research dominated by studies of persistent cases (those that retain HCU status over time). Since the two populations are likely to be different, studying incident cases of HCU provides important information to inform health policies and interventions. Third, it directly estimates variation across a number of cost categories using two variance components, which has never been done in the past. Finally, to deal with the large proportion of zero costs in the data (i.e. no healthcare use), we used two part-models which have been shown to provide better estimates than models that ignore the over-representation of zeros [48] .

We note some limitations. While the study's cost data captures public expenditures in the most expensive cost categories such as hospital admissions, physician billings, rehabilitation or home care, cost data for some components may be incomplete. For pharmaceutical care, copayment is not included in the ODB cost and, more importantly, the cost of some chemotherapy not covered by the ODB is not captured by the study, especially the costs incurred in outpatient cancer clinics [40]. The LTC costs do not include accommodation charges unless the patient's stay is subsidized by the government. Another
Canadian-based study into $\mathrm{HCU}$ that used the same source of administrative data but examined the entire HCU population across only 5 cost components estimated the extent of unaccounted for cost data at 7\% [7]. However, since data on seniors is usually more complete, our conservative estimate is that less than $5 \%$ of government expenditures on individual health services to seniors might not have been included in this study, hence their impact on the results is close to negligible. Secondly, this study did not account for the supply side of the examined variation as the data were not available for analysis. That would require access to LHIN-based data on the number of physicians, hospital and LTC beds, $\mathrm{HC} / \mathrm{CCAC}$ staff. Instead, our approach standardized for the effect of patient needs. Similarly, we did not have access to several variables which could partially explained some of the variation between LHINs (e.g. patient preferences, health behaviors, education, etc). Further, we encountered model convergence and parameter estimation issues when running models for the non-HCU' cost components using the total non-HCU population. To address this, we re-fitted the models on a random sample of the population. Depending on the cost component, the sample size ranged from 30 to $100 \%$.However, convergence issues in mixed effects models run on the entire population are not uncommon with very large datasets [67]. This is a limitation that in our opinion was alleviated by low discrepancy in the estimates generated by RE models compared to FE models run on the full size of the non-HCU population. Not surprisingly, as $30 \%$ of the non-HCU population is still a large enough sample (i.e., > 150,000 individuals). Finally, some may argue that a smaller unit of analysis would be preferable to evaluate regional variation. Using a smaller unit (sub-LHINs in our case) could unmask heterogeneity at the more local level. We did not have information on sub-LHINs and therefore we could not conduct these analyses. However, the choice of LHINs as the unit of analysis is supported by the fact that the boundaries of LHINs were developed with local patterns of care provision in mind [68].

\section{Conclusions}

Risk-adjusted allocation of healthcare resources to seniors across Ontario is similar across health districts, more so for HCU than non-HCU. However, when analyzed in combination with risk-adjusted mortality, we identified important variation in the cost-mortality relationship among LHINs which needs to be further explored. The traditional drivers of costs and mortality had a weak impact on the observed variation in the outcomes among both HCU and non-HCU, but largely explained the probability of healthcare system access. 


\section{Additional files}

Additional file 1: Intra-class coefficients (ICC). Provides details on ICC calculation for costs and mortality. (DOCX $21 \mathrm{~kb}$ )

Additional file 2: Model specification and other statistical formulas used in statistical analysis. Provides details on model specification and formulas used in calculations. (DOCX $17 \mathrm{~kb}$ )

Additional file 3: A-B. Variation (by LHIN) in patient baseline individua and care characteristics, pre-incident year. The files provide information on the variation in individual and care characteristics between the 14 LHINs: for HCU (2A) and non-HCU (2B). (DOCX $30 \mathrm{~kb}$ )

Additional file 4: A-C. Observed and adjusted healthcare care expenditures (total and by cost component) and mortality among HCU and non-HCU, incident year. The file provides details observed and adjusted values and model fit. (DOCX $99 \mathrm{~kb}$ )

Additional file 5: Estimate coefficients, healthcare care expenditures among HCU and non-HCU, total costs and cost components, incident year. The file provides details on regression coefficients, including the estimates of variance components. (DOCX $49 \mathrm{~kb}$ )

\section{Abbreviations}

ACGs: Johns Hopkins Adjusted Clinical Groups; ADGs: Johns Hopkins Aggregated Diagnosis Groups; BC: British Columbia, Canada; CAD: Canadian dollar; CHF: Congestive heart failure; COPD: Chronic obstructive pulmonary disease; CV: Coefficient of variation; DM: Diabetes; EDCs: John Hopkins Expanded Diagnosis Clusters; FY: Fiscal year; GLM: Generalized linear models; HCU: High-cost user; ICC: Intraclass coefficient; ICES: Institute for Clinical Evaluative Sciences; LHIN: Local Health Integration Networks; LRT: Likelihood ratio test; MI: Myocardial infarction; QGIS: Quantum geographic information system; RA: Rheumatoid arthritis; RIO: Rural Index of Ontario; SD: Standard deviation; SDD: Absolute Standardized difference; US: United States

\section{Acknowledgements}

Parts of this material are based on data and/or information compiled and provided by the Canadian Institute for Health Information (CIHI). However, the analyses, conclusions, opinions and statements expressed in the material are those of the authors and not necessarily those of $\mathrm{CIHI}$. We thank IMS Brogan Inc. for use of their Drug Information Database.

\section{Funding}

This work is supported by personnel funding and in-kind analyst and epidemiologist support from the Ontario Drug Policy Research Network (ODPRN), and personnel awards from the Canadian Institutes of Health Research (CIHR) Drug Safety and Effectiveness Cross-Disciplinary Training (DSECT) Program, the Program for Assessment of Technology in Health (PATH), The Research Institute of St Joe's Hamilton, St Joseph's Healthcare Hamilton, and an Ontario Graduate Scholarship (OGS). The work also is supported by the Institute for Clinical Evaluative Sciences (ICES). ODPRN and ICES are funded by grants from the Ontario Ministry of Health and Long-Term Care (MOHLTC) and the Ontario Strategy for Patient-Orientated Research (SPOR) Support Unit, which is supported by the Canadian Institutes of Health Research and the Province of Ontario. The opinions, results, and conclusions reported in this article are those of the authors and are independent from the funding sources. The funding bodies had no role in the design of the study, the collection, analysis, interpretation of data and in writing the manuscript. No endorsement by the Ontario MOHLTC is intended or should be inferred.

\section{Availability of data and materials}

The dataset from this study is held securely in coded form at the Institute for Clinical Evaluative Sciences (ICES). While data sharing agreements prohibit ICES from making the dataset publicly available, access may be granted to those who meet pre-specified criteria for confidential access, available at <http:// www.ices.on.ca/DAS>. The full dataset creation plan and underlying analytic code are available from the authors upon request, understanding that the programs may rely upon coding templates or macros that are unique to ICES.

\section{Authors' contributions}

SM, JET, AH, JL, JMP, TG, AC, LM, JRG conceptualized the study. SM, JET, AH, $J L, A C, J R G, L M, J M P, T G, W K$ have contributed to its design. JMP, WK, TG were instrumental in creating datasets. SM prepared the initial draft of the manuscript and revised it based on co- authors' feedback: JET, AH, JL, JMP, $T G, J R G, L M, A C$, WK provided comments to the initial draft, further revisions, read and approved the final manuscript. The responsibility of study implementation lies with the principal investigator (SM) that is supported and supervised primarily by JET.

Ethics approval and consent to participate

The protocol for this study was reviewed and approved by the Hamilton Integrated Research Ethics Board (ID\#1715-C).

\section{Consent for publication \\ N/A}

\section{Competing interests}

The authors declare that they have no competing interests.

\section{Publisher's Note}

Springer Nature remains neutral with regard to jurisdictional claims in published maps and institutional affiliations.

\section{Author details}

'Department of Health Research Methods, Evidence, and Impact, McMaster University, Hamilton, ON, Canada. ${ }^{2}$ Programs for Assessment of Technology in Health (PATH), The Research Institute of St. Joe's Hamilton, St. Joseph's Healthcare, Hamilton, ON, Canada. ${ }^{3}$ Division of Geriatric Medicine, Department of Medicine, McMaster University, Hamilton, ON, Canada. ${ }^{4}$ Division of Clinical Pharmacology and Toxicology, Department of Medicine, McMaster University, Hamilton, ON, Canada. ${ }^{5}$ Geriatric Education and Research in Aging Sciences Centre, Hamilton Health Sciences, Hamilton, ON, Canada. ${ }^{6}$ Institute for Clinical Evaluative Sciences (ICES), Toronto, ON, Canada. ${ }^{7}$ Center for Health Economics and Policy Analysis (CHEPA), McMaster University, Hamilton, Canada. ${ }^{8}$ Département de Médecine Sociale et Préventive, Faculté de Médecine, Université Laval, Quebec City, QC, Canada. ${ }^{9}$ Centre de recherche du CHU de Québec, Université Laval, Axe Santé des Populations et Pratiques Optimales en Santé, Québec City, QC, Canada. ${ }^{10}$ Biostatistics Unit, Father Sean O'Sullivan Research Centre, St Joseph's Healthcare, Hamilton, ON, Canada. ${ }^{11}$ Institute of Health Policy, Management and Evaluation, University of Toronto, Toronto, ON, Canada. ${ }^{12}$ Leslie Dan Faculty of Pharmacy, University of Toronto, Toronto, Canada. ${ }^{13} \mathrm{Li}$ Ka Shing Knowledge Institute, St. Michael's Hospital, Toronto, ON, Canada.

Received: 2 April 2018 Accepted: 17 October 2018

Published online: 01 November 2018

\section{References}

1. Blumenthal D, Chernof B, Fulmer T, Lumpkin J, Selberg J. Caring for high-need, high-cost patients - an urgent priority. N Engl J Med. 2016;375(10):909-11.

2. Hayes SL, Salzberg CA, McCarthy D, et al. High-Need, High-Cost Patients: Who Are They and How Do They Use Health Care? A Population-Based Comparison of Demographics, Health Care Use, and Expenditures. Issue brief (Commonwealth Fund). 2016;26:1-14.

3. Rais S, Nazerian A, Ardal S, Chechulin Y, Bains N, Malikov K. High-cost users of Ontario's healthcare services. Healthcare policy = Politiques de sante. 2013:9(1):44-51.

4. Lee JY, Muratov S, Tarride J-E, Holbrook AM. Managing high-cost healthcare users: the international search for effective evidence-supported strategies. J Am Geriatr Soc. 2018;66(5):1002-8.

5. Statistics Canada: Population by year, by province and territory [ http:// www.statcan.gc.ca/tables-tableaux/sum-som/101/cst01/demo02a-eng.htm ]. Accessed 25 Jan 2018

6. Roos NP, Shapiro E, Tate R. Does a small minority of elderly account for a majority of health care expenditures? A sixteen-year perspective. The Milbank Quarterly. 1989;67(3-4):347-69.

7. Wodchis WP, Austin PC, Henry DA. A 3-year study of high-cost users of health care. Cmaj. 2016;188(3):182-8.

8. Geographic Variations in Health Care. Focus on Health- OECD Health Policy Studies [ https://www.oecd.org/els/health-systems/FOCUS-on-GeographicVariations-in-Health-Care.pdf ]. Accessed 12 Feb 2018. 
9. Kim AM, Park JH, Kang S, Hwang K, Lee T, Kim Y. The effect of geographic units of analysis on measuring geographic variation in medical services utilization. J Prev Med Public Health. 2016;49(4):230-9.

10. Lougheed MD, Garvey N, Chapman KR, Cicutto L, Dales R, Day AG, Hopman WM, Lam M, Sears MR, Szpiro K, et al. The Ontario asthma regional variation study: emergency department visit rates and the relation to hospitalization rates. Chest. 2006;129(4):909-17.

11. Feasby TE, Quan H, Ghali WA. Geographic variation in the rate of carotid endarterectomy in Canada. Stroke. 2001;32(10):2417-22.

12. Feinberg $A E$, Porter J, Saskin R, Rangrej J, Urbach DR. Regional variation in the use of surgery in Ontario. CMAJ open. 2015;3(3):E310-6.

13. Hogan DB, Maxwell CJ, Fung TS, Ebly EM. Regional variation in the use of medications by older Canadians--a persistent and incompletely understood phenomena. Pharmacoepidemiol Drug Saf. 2003;12(7):575-82.

14. Morgan SG, Cunningham CM, Hanley GE. Individual and contextual determinants of regional variation in prescription drug use: an analysis of administrative data from British Columbia. PLoS One. 2010; 5(12):e15883.

15. Newhouse JP, Garber AM, Graham RP, McCoy MA, Mancher M, Kibria A. Variation in health care spending: target decision making, not geography. In: Committee on geographic variation in health care spending and promotion of high-value care; board on health care services; institute of Medicine; 2013.

16. Elliott S, Fisher M, David E, Wennberg M, Thrse A, Stukel P, Daniel J, Gottlieb MFL, Lucas P, Étoile L, Pinder M. The implications of regional variations in Medicare spending. Part 2: health outcomes and satisfaction with care. Ann Intern Med. 2003;138(4):288-98.

17. Fisher E, Goodman D, Skinner J, Bronner K. Health Care Spending, Quality, and Outcomes. The Dartmouth Insititute for Health Policy Research and Clinical Practice, 2009

18. Fisher ES, Wennberg DE, Stukel TA, Gottlieb DJ, Lucas FL, Pinder ÉL. The implications of regional variations in Medicare spending. Part 1: the content, quality, and accessibility of care. Ann Intern Med. 2003;138(4):273-87.

19. Zuckerman SWT, Berenson R, Hadle J. Clarifying sources of geographic differences in Medicare spending. N Engl J Med. 2010;363:54-62.

20. Lavergne MR, Barer M, Law MR, Wong ST, Peterson S, McGrail K. Examining regional variation in health care spending in British Columbia, Canada. Health Policy. 2016;120(7):739-48.

21. Brooks GA, Li L, Uno H, Hassett MJ, Landon BE, Schrag D. Acute hospital care is the chief driver of regional spending variation in Medicare patients with advanced cancer. Health affairs (Project Hope). 2014;33(10):1793-800.

22. Ellis RP, Fiebig DG, Johar M, Jones G, Savage E. Explaining health care expenditure variation: large-sample evidence using linked survey and health administrative data. Health Econ. 2013;22(9):1093-110.

23. Bevan G: Using information on variation in rates of supply to questoin professional discretion in public services. 2004.

24. Kephart G, Asada Y. Need-based resource allocation: different need indicators, different results? BMC Health Serv Res. 2009;9:122.

25. O'Neill J, Tabish H, Welch V, Petticrew M, Pottie K, Clarke M, Evans T, Pardo Pardo J, Waters E, White $H$, et al. Applying an equity lens to interventions: using PROGRESS ensures consideration of socially stratifying factors to illuminate inequities in health. J Clin Epidemiol. 2014;67(1):56-64.

26. Struikmans H, Aarts MJ, Jobsen JJ, Koning CC, Merkus JW, Lybeert ML, Immerzeel J, Poortmans PM, Veerbeek L, Louwman MW, et al. An increased utilisation rate and better compliance to guidelines for primary radiotherapy for breast cancer from 1997 till 2008: a population-based study in the Netherlands. Radiother Oncol. 2011;100(2):320-5.

27. Bierman AS, Shack AR, Johns A, for the POWER Study. Achieving health equity in Ontario: opportunities for intervention and improvement. In: Bierman AS, editor. Project for an Ontario Women's health evidence-based report. Volume 2 ed. Toronto: St. Michael's Hospital and the Institute for Clinical Evaluative Sciences; 2012.

28. Ohinmaa A, Zheng Y, Jeerakathil T, Klarenbach S, Hakkinen U, Nguyen T, Friesen D, Ruseski J, Kaul P, Ariste R, et al. Trends and regional variation in hospital mortality, length of stay and cost in Hospital of Ischemic Stroke Patients in Alberta accompanying the provincial reorganization of stroke care. J Stroke Cerebrovasc Dis. 2016;25(12):2844-50.

29. Joumard, I., André C., Nicq C. "Health Care Systems: Efficiency and Institutions", OECD Economics Department Working Papers, No. 769. Paris: OECD Publishing; 2010. https://doi.org/10.1787/5kmfp51f5f9t-en.

30. Allin S, Veillard J, Wang L, Grignon M. How can health system efficiency be improved in Canada? Healthcare Policy. 2015;11(1):33-45.
31. Zhang Y, Baik SH, Fendrick AM, Baicker K. Comparing local and regional variation in health care spending. N Engl J Med. 2012;367(18):1724-31.

32. Hong YR, Kates F, Song SJ, Lee N, Duncan RP, Marlow NM. Benchmarking implications: analysis of Medicare accountable care organizations spending level and quality of care. J Healthc Qual. 2018. https://doi.org/10.1097/JHQ. 0000000000000123 . [Epub ahead of print].

33. Skinner J. Causes and consequences of regional variations in health care. In: Handbook of health economics, vol. 2011. Volume 2 ed. p. 45-93.

34. Corallo AN, Croxford R, Goodman DC, Bryan EL, Srivastava D, Stukel TA. A systematic review of medical practice variation in OECD countries. Health Policy. 114(1):5-14.

35. Rosenberg BL, Kellar JA, Labno A, Matheson DH, Ringel M, VonAchen $P$, Lesser RI, Li Y, Dimick JB, Gawande AA, et al. Quantifying geographic variation in health care outcomes in the United States before and after riskadjustment. PLoS One. 2016;11(12):e0166762.

36. Muratov S, Lee J, Holbrook A, Paterson JM, Guertin JR, Mbuagbaw L, Gomes T, Khuu W, Pequeno P, Costa AP, et al. Senior high-cost healthcare users' resource utilization and outcomes: a protocol of a retrospective matched cohort study in Canada. BMJ Open. 2017;7(12):e018488.

37. Fitzpatrick T, Rosella LC, Calzavara A, Petch J, Pinto AD, Manson H, Goel V, Wodchis WP. Looking beyond income and education: socioeconomic status gradients among future high-cost users of health care. Am J Prev Med. 2015;49(2):161-71.

38. Rosella LC, Fitzpatrick T, Wodchis WP, Calzavara A, Manson H, Goel V. Highcost health care users in Ontario, Canada: demographic, socio-economic, and health status characteristics. BMC Health Serv Res. 2014;14:532.

39. Institute for Clinical Evaluative Sciences (ICES); www.ices.on.ca . Accessed 10 Dec 2017.

40. Wodchis WP, Bushmeneva K, Nikitovic M, McKillop I. Guidelines on personlevel costing using administrative databases in Ontario. In: Working Paper Series, vol. 1. Toronto: Health System Performance Research Network; 2013.

41. Ontario's Local Health Integration Networks. [www.Ihins.on.ca ]. Accessed 6 Feb 2018.

42. Local Health System Integration Act, 2006, S.O. 2006, c. 4 (amended 2017). [ https://www.ontario.ca/laws/statute/06104 ]. Accessed 26 Jan 2018.

43. Kralj B. Measuring 'rurality' for purposes of health-care planning: an empirical measure for Ontario. Ont Med Rev. 2000;67(9):33-52.

44. The Johns Hopkins ACG ${ }^{\oplus}$ System Version 10.0 Technical Reference Guide. In.: Department of Health Policy and Management, Johns Hopkins University, Bloomberg School of Public Health; 2014.

45. Gershon AS, Wang C, Guan J, Vasilevska-Ristovska J, Cicutto L, TO T. Identifying individuals with physcian diagnosed COPD in health administrative databases. Copd. 2009;6(5):388-94.

46. Schultz SE, Rothwell DM, Chen Z, Tu K. Identifying cases of congestive heart failure from administrative data: a validation study using primary care patient records. Chronic Dis Inj Can. 2013;33(3):160-6.

47. Austin PC. Balance diagnostics for comparing the distribution of baseline covariates between treatment groups in propensity-score matched samples. Stat Med. 2009:28(25):3083-107.

48. Buntin MB, Zaslavsky AM. Too much ado about two-part models and transformation? Comparing methods of modeling Medicare expenditures. J Health Econ. 2004;23(3):525-42.

49. Liu L, Cowen ME, Strawderman RL, Shih Y-CT. A flexible two-part random effects model for correlated medical costs. J Health Econ. 2010;29(1):110-23.

50. Basu A, Manning WG, Mullahy J. Comparing alternative models: log vs cox proportional hazard? Health Econ. 2004;13(8):749-65.

51. Gregori D, Petrinco M, Bo S, Desideri A, Merletti F, Pagano E. Regression models for analyzing costs and their determinants in health care: an introductory review. Int J Qual Health Care. 2011;23(3):331-41.

52. de Vries EF, Heijink R, Struijs JN, Baan CA. Unraveling the drivers of regional variation in healthcare spending by analyzing prevalent chronic diseases. BMC Health Serv Res. 2018;18(1):323.

53. Liu L, Ma JZ, Johnson BA. A multi-level two-part random effects model, with application to an alcohol-dependence study. Stat Med. 2008;27(18): 3528-39.

54. Tooze JA, Grunwald GK, Jones RH. Analysis of repeated measures data with clumping at zero. Stat Methods Med Res. 2002;11(4):341-55.

55. Austin PC, Merlo J. Intermediate and advanced topics in multilevel logistic regression analysis. Stat Med. 2017;36(20):3257-77.

56. Nakagawa S, Johnson PCD, Schielzeth $\mathrm{H}$. The coefficient of determination R2 and intra-class correlation coefficient from generalized linear mixedeffects models revisited and expanded. J R Soc Interface. 2017;14(134): 20170213. 
57. D'Errigo P, Tosti ME, Fusco D, Perucci CA, Seccareccia F. Use of hierarchical models to evaluate performance of cardiac surgery centres in the Italian CABG outcome study. BMC Med Res Methodol. 2007;7:29.

58. MacKenzie TA, Grunkemeier GL, Grunwald GK, O'Malley AJ, Bohn C, Wu Y, Malenka DJ. A primer on using shrinkage to compare in-hospital mortality between centers. Ann Thorac Surg. 2015;99(3):757-61.

59. Hadley J, Reschovsky JD. Medicare spending, mortality rates, and quality of care. Int J Health Care Finance Econ. 2012;12(1):87-105.

60. Lippi G, Mattiuzzi C, Cervellin G. No correlation between health care expenditure and mortality in the European Union. Eur J Intern Med. 2016;32:e13-4.

61. Gallet CA, Doucouliagos H. The impact of healthcare spending on health outcomes: a meta-regression analysis. Soc Sci Med. 2017;179:9-17.

62. Cohen D, Manuel DG, Tugwell P, Sanmartin C, Ramsay T. Does higher spending improve survival outcomes for myocardial infarction? Examining the cost-outcomes relationship using time-varying covariates. Health Serv Res. 2015;50(5):1589-605.

63. Stargardt T, Schreyogg J, Kondofersky I. Measuring the relationship between costs and outcomes: the example of acute myocardial infarction in German hospitals. Health Econ. 2014;23(6):653-69.

64. Stukel TA, Fisher ES, Alter DA, Guttmann A, Ko DT, Fung K, Wodchis WP, Baxter NN, Earle CC, Lee DS. Association of Hospital Spending Intensity with Mortality and Readmission Rates in Ontario hospitals. Jama. 2012;307(10):1037-45.

65. McKay NL, Deily ME. Comparing high- and low-performing hospitals using risk-adjusted excess mortality and cost inefficiency. Health Care Manag Rev. 2005;30(4):347-60.

66. Zhang M, Strawderman RL, Cowen ME, Wells MT. Bayesian inference for a two-part hierarchical model. J Am Stat Assoc. 2006;101(475):934-45.

67. Gebregziabher M, Egede L, Gilbert GE, Hunt K, Nietert PJ, Mauldin P. Fitting parametric random effects models in very large data sets with application to VHA national data. BMC Med Res Methodol. 2012;12:163.

68. Health Analyst's Toolkit. In.: Health Analytics Branch, Ontario Ministry of Health and Long-Term Care; 2012.

Ready to submit your research? Choose BMC and benefit from:

- fast, convenient online submission

- thorough peer review by experienced researchers in your field

- rapid publication on acceptance

- support for research data, including large and complex data types

- gold Open Access which fosters wider collaboration and increased citations

- maximum visibility for your research: over $100 \mathrm{M}$ website views per year

At $\mathrm{BMC}$, research is always in progress.

Learn more biomedcentral.com/submissions 